\title{
Optic Nerve Hypoplasia
}

National Cancer Institute

\section{Source}

National Cancer Institute. Optic Nerve Hypoplasia. NCI Thesaurus. Code C98999.

A congenital abnormality characterized by the underdevelopment of the optic nerve. 